\title{
Resolução da Situação-Problema e Desfecho em Histórias de Crianças de 7 e 9 Anos
}

Resolution Of The Problem-Situation And Outcome In Stories For Children At 7 And 9 Years

Resolución De La Situación-Problema Y Cierre En Historias Para Niños Con Edad Entre 07 Y 09 Años.

Maria do Rosário de

Fátima Rodrigues \& Fernanda Costa Vilela

Centro Universitário do Leste de Minas Gerais
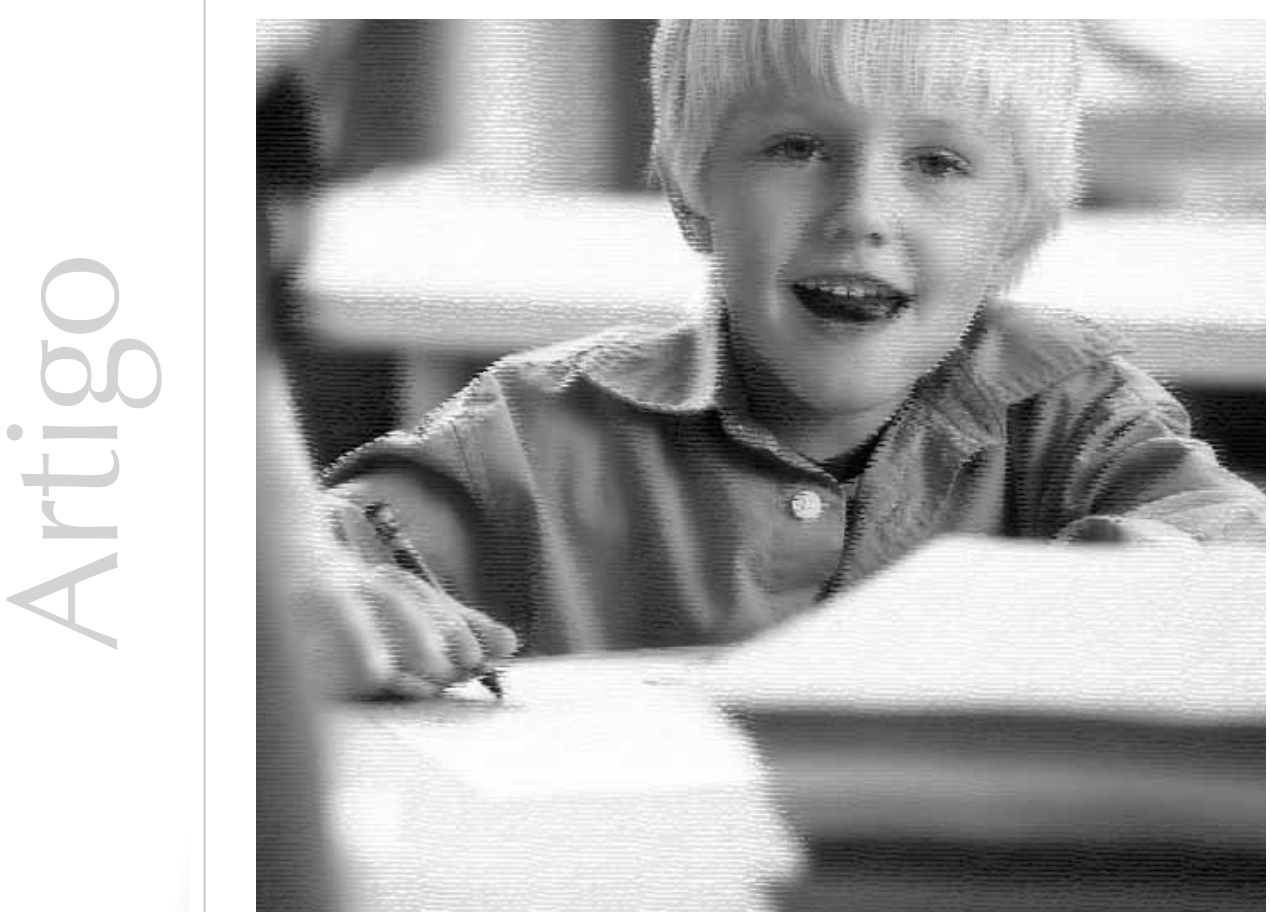
Resumo: O objetivo deste trabalho foi analisar a influência da situação de produção de textos narrativos, elaborados por crianças de 7 e 9 anos, em uma perspectiva psicogenética. Participaram deste estudo 23 alunos da primeira série e 50 da terceira. Após a escrita de uma história em situação livre, foram realizadas três sessões individuais com atividades de consciência metatextual, a saber: na sessão 1, apresentaram-se histórias curtas com suas partes constituintes marcadas em cores diferentes; na sessão seguinte, montou-se um quebra-cabeça em analogia às partes de uma história. Finalmente, houve a montagem de um baralho de história, e depois escreveu-se outra história em situação livre. Foi feita a comparação dos níveis da narrativa e características, da resolução da situação-problema e do desfecho, antes e depois da intervenção. Entre o pré e o pós-teste, os resultados da primeira série sinalizaram o aparecimento de histórias e de desfechos mais elaborados. Na terceira série, também houve aumento do número de histórias mais elaboradas, bem como da característica resolução da situação-problema, que se mostrou mais explicada. Conclui-se que as sessões de consciência metatextual aumentaram as habilidades de escrita das histórias, especialmente na terceira série, sendo mais apreciáveis nas características do que nos níveis das narrativas.

Palavras-chave: Crianças em idade escolar. Estudantes do ensino fundamental. Habilidades para escrita. Metalinguística. Narrativas.

Abstract: The aim of this study was to analyse the production of narrative texts drew up by children aged 7 to 9 . Twenty three students from the first grade and fifty from the third grade participated in this study. After writing a free story, three individual sections on metatextual consciousness activities were performed: in the first section, short stories marked with different colours were presented; on the next section, a puzzle game was assembled in analogy to the parts of a story, finally, there was an assembly of a pack of cards of a story. Later, a free story was written. A comparison of the levels of narrative and characteristics was made, as well as of the resolution of the problem and of the outcome before and after the intervention. Between the pre and the post test, the results of the first grade indicated the appearance of more elaborated stories. On the third grade there was an increase on the number of elaborated stories and the characteristics of the problems were also more detailed. We can conclude that these metatextual sections increased the abilities in writing stories, especially in the third grade, being more appreciated by the characteristics than by the levels of narrative.

Keywords: School age children. Elementary school students. Writing skills. Narratives. Metalinguistics.

Resumen: El objetivo de este trabajo ha sido analizar la influencia de la situación de producción de textos narrativos, elaborados por niños con edad entre 07 y 09 años, en una perspectiva psicogenética. Han participado de este estudio 23 alumnos del primer grado y 50 del tercer grado. Luego de la escrita de una historia en situación libre, han sido llevadas a cabo tres sesiones individuales con actividades de conciencia meta-textual, descriptas a continuación: en la sesión 01, se han presentado historias cortas con sus partes constituyentes realzadas en colores distintos; en la sesión siguiente, se ha montado un rompecabezas en analogía a las partes de una historia. Finalmente, se ha hecho el montaje de una baraja de historia, y luego se ha escrito otra historia en situación libre. Se ha hecho una comparación de los niveles de la narrativa y características, de la resolución de la situación-problema y del cierre, antes y después de la intervención. Entre el pre-teste y el pos-teste, los resultados del primer grado han señalado el aparecimiento de historias y de cierres más elaborados. Asimismo, en el tercer grado ha habido un aumento del número de historias más elaboradas, así como de la característica resolución de la situación-problema, que se ha mostrado más explicada. Se concluye que las sesiones de conciencia meta-textual han aumentado las habilidades de escrita de las historias, especialmente en el tercer grado, y son más apreciables en las características que en los niveles de las narrativas.

Palabras clave: Niños en edad escolar. Estudiantes de 1er grado. Habilidades para escrita. Metalingüística. Narrativas.

A palavra metalinguagem é formada do prefixo grego meta, que expressa a ideia de mistura e sucessão. Assim, à palavra linguagem, o prefixo acrescenta o sentido de modificação, atribuindo-lhe o significado de mudança (Walty \& Cury, 1999). Trata-se de uma linguagem utilizada para descrever outra, ou ainda, pode ser entendida como uma função da linguagem, na qual esta constitui o objeto a ser descrito.

No ensaio Linguística e Poética, Jakobson (s.d.) esquematiza as funções da linguagem, descrevendo, dentre elas, a metalinguística, considerada o nível da linguagem que versa sobre si mesma. Segundo ele, todo o 
Sobre o

desenvolvimento

do domínio

do esquema

narrativo,

segundo exame

de Silva e Spinillo

(2000), existe

uma progressão

na escrita de

narrativas, que é

pouco expressiva

no primeiro ano

de escolaridade,

mas que se torna

mais expressiva

no segundo e no

terceiro anos. processo de aprendizado da linguagem é constituído por operações metalinguísticas, principalmente quando se trata da aquisição, pela criança, da língua materna.

Há consenso na literatura de que existe relação entre aprendizagem da língua escrita e consciência linguística, denominada habilidade metalinguística, que é considerada a capacidade de manejar as organizações linguísticas de maneira consciente. Esta é considerada uma atividade intencional do indivíduo ao tratar o texto como um objeto de análise. Em trabalho realizado sobre habilidades metalinguísticas e linguagem escrita, nas pesquisas brasileiras, Maluf, Zanella e Pagnez (2006) perceberam crescente interesse pelo tema, mas enfatizaram que dissertações e teses foram mais numerosas do que artigos, o que sinaliza a necessidade de maior disseminação do conhecimento produzido. Nesse levantamento, as autoras descreveram que as habilidades metalinguísticas estudadas foram: consciência fonológica, habilidade ortográfica, sintática, lexical, semântica, morfológica e metatextual. Entretanto, ressaltaram que ainda são escassos os estudos de intervenção nos quais possa haver a verificação de aspectos causais que repercutem sobre as habilidades envolvidas.

Em revisão de literatura realizada por Spinillo e Simões (2003), os estudos empíricos sobre consciência metatextual se voltavam para os aspectos micro e macrolinguísticos do texto, sendo os primeiros relacionados aos coesivos e à pontuação, e o segundo grupo, ao estudo sobre a reflexão do leitor em relação à organização do texto, seja no seu conteúdo, seja na sua estrutura. Isso remete finalmente aos gêneros textuais, dentre os quais o mais investigado é a história. Sobre a estrutura do texto, o foco se deslocaria do conteúdo para sua configuração linguística. Segundo as mesmas autoras, nesse enfoque, os estudos são raros e recentes. O que se tem em comum entre eles é a percepção de que a consciência metatextual se desenvolve entre 5 e 9 anos, sendo evidenciada aos 8 e 9 anos. A seguir, serão apresentadas as características gerais desse desenvolvimento.

Sobre o desenvolvimento do domínio do esquema narrativo, segundo exame de Silva e Spinillo (2000), existe uma progressão na escrita de narrativas, que é pouco expressiva no primeiro ano de escolaridade, mas que se torna mais expressiva no segundo e no terceiro anos. Essa descrição permitiu verificar que, em análise do efeito das séries sobre a produção escrita, as histórias das crianças da terceira série tinham estrutura narrativa mais elaborada. Como visto, a escolarização é fator importante no desenvolvimento do domínio do esquema narrativo.

Estudo de Silva e Spinillo (2000) examinou a influência de diferentes situações de produção na escrita de histórias, de crianças da primeira à quarta série do ensino fundamental, e identificou que as histórias mais elaboradas foram escritas a partir de uma sequência de gravuras e de uma história ouvida, em detrimento da produção livre e escrita de uma história contada pela própria criança. Entretanto, essa influência variou em função das séries, a saber, as crianças das séries mais adiantadas escreveram narrativas elaboradas em todas as situações.

Em outro estudo sobre o desenvolvimento do esquema narrativo de história, Spinillo (2001) apresentou uma categorização, utilizada neste trabalho, que será citada a seguir. Na categoria I, consideraram-se as produções nas quais havia introdução da cena e dos personagens, com a presença de marcadores linguísticos convencionais do começo de uma história, do tipo Era uma vez. As histórias da categoria II apresentavam uma ação que sugeria o esboço de uma situação-problema. Na categoria III, as histórias mostravam tentativas de resolução da situação-problema, sem que fossem 
explicitados os meios utilizados. Finalmente, na categoria IV, as histórias eram completas, com uma estrutura narrativa elaborada, bem como o desfecho da trama.

Para se avançar um pouco mais nessa descrição evolutiva, será citada a pesquisa de Brandão e Spinillo (1998), na qual examinaram a relação entre o tipo de resposta fornecido e os elementos estruturais de uma história, a saber: situação-problema, resolução da situação-problema e conclusão, seguida da descrição das características relativas à resolução da situação-problema. As autoras apresentaram tarefas de reprodução de uma história ouvida e perguntas inferenciais sobre a mesma história a 40 crianças, divididas em dois grupos de idade: quatro e seis anos. Observaram que, aos quatro anos, as respostas consideradas corretas foram mais frequentes diante das perguntas relacionadas à identificação da situação-problema do que nas perguntas sobre a resolução da situação-problema e sobre a consequência ou desfecho. Aos seis anos, as respostas precisas ocorreram mais nas questões relacionadas à identificação da situaçãoproblema e à consequência, ou desfecho, do que nas perguntas sobre a resolução da situação-problema. Como visto, há uma diferença evolutiva quanto à identificação dos elementos estruturais de uma história.

No intuito de contextualizar a ascendência dos tipos de resolução da situação-problema articulados ao desfecho da história, a seguir, serão citados os níveis de resolução da situação-problema utilizados neste trabalho, por meio do sistema de análise de Silva e Spinillo (2000), a partir do qual são mencionadas as seguintes características: resolução da situação-problema sem coerência, não explicada e explicada.

sem coerência foi considerada um tipo elementar de resolução.

\section{A resolução da situação-problema sem coerência foi considerada um tipo elementar de resolução}

Essa característica se evidenciou quando a história apresentava uma resolução da situação-problema não elaborada e que geralmente está presente entre narrativas nas quais, além da introdução da cena e dos personagens, com início convencional, há uma ação que sugere o esboço de uma situação-problema, embora esta não seja claramente explicada. A característica resolução da situação-problema não explicada foi considerada quando a história apresentava um tipo de resolução coerente da situação-problema, mas não explicada, que geralmente está presente em narrativas nas quais, além de uma ação que sugere o esboço de uma situação-problema, há tentativas de resolução. Finalmente, a resolução da situação-problema explicada foi considerada presente quando existia um tipo elaborado de resolução dessa situação (Rodrigues, 2007).

Dessa forma, foram enfatizadas algumas características da resolução da situaçãoproblema nas narrativas. Entretanto, para finalizar essa descrição evolutiva, serão mencionadas as características do desfecho de uma história, por meio do sistema de análise de Spinillo e Martins (1997), a partir do qual se abordará as seguintes características: desfecho não elaborado, pouco ou elaborado. A produção verbal de histórias coerentes, por crianças de 6-7 anos, foi analisada pelos autores em função de indicadores específicos, agrupados em um sistema de análise que expressava diferentes níveis no estabelecimento da coerência, no intuito de contextualizar a ascendência dos tipos de desfecho da história, articulados a outros indicadores da coerência de uma narrativa, como manutenção do personagem principal, manutenção do tema ao longo de 
Segundo

Rodrigues (2007),

as crianças, ao

demonstrarem

em suas

narrativas as

características,

tais como

resolução

da situação-

problema e

desfecho,

apresentam, também,

aspectos do

seu próprio

desenvolvimento. toda a narrativa e evento principal ou situaçãoproblema. Nessa análise, verificaram que crianças nessa faixa-etária têm dificuldades em definir e manter o tópico ao longo da narrativa e, principalmente, em elaborar um desfecho relacionado com o evento principal e com os episódios narrados. Segundo os autores, o desfecho parece ser o indicador mais difícil de ser estabelecido na produção de uma história coerente. Desfechos elaborados são geralmente observados em histórias com outros indicadores, também elaborados, como, por exemplo, personagens, eventos e tópicos da narração definidos e mantidos no decorrer da história, que são favoravelmente influenciados pela aquisição da leitura e da escrita.

Nesta pesquisa, buscou-se ampliar a compreensão sobre como as crianças podem escrever melhores narrativas em uma situação de produção. Segundo Rodrigues (2007), as crianças, ao demonstrarem em suas narrativas as características, tais como resolução da situação-problema e desfecho, apresentam, também, aspectos do seu próprio desenvolvimento. Logo, percebese que aspectos cognitivos e evolução da narrativa andam de mãos dadas. Ora, se as crianças estão suscetíveis de desenvolver as características da narrativa, da resolução e do desfecho elaborados, a situação de produção favorável tende a influenciar da mesma forma, ancorada na idade e na série escolar, de modo favorável ao desenvolvimento da capacidade de contar histórias. Esse dado vem confirmar a importância de estudos não só sobre as situações de produção mas também, e principalmente, sobre a adequação dessas situações às crianças, considerando o seu desenvolvimento. Assim buscou-se averiguar as relações entre tipos de desfecho, em crianças de 7 anos, na primeira série, como também averiguar as relações entre tipos de resolução da situação-problema, em crianças de 9 anos, na terceira série, ambas em uma situação de produção de escrita, a partir da consciência metatextual, conforme Ferreira e Spinillo (2003).
Nesse sentido, o objetivo deste trabalho foi analisar, em uma perspectiva psicogenética, a influência da situação de produção de textos narrativos, a partir da consciência metatextual, elaborados por crianças de 7 e 9 anos, por meio da comparação das características, da resolução da situação-problema e do desfecho, juntamente aos níveis da narrativa, antes e depois das intervenções, como situação de produção do texto narrativo.

\section{Método}

\section{Participantes}

Os participantes desta pesquisa foram 73 crianças (38 meninas e 35 meninos), com idades de 7 e 9 anos, cursando a $1^{1}$ e e $3^{\underline{a}}$ séries do ensino fundamental, respectivamente, provenientes de duas escolas públicas de uma cidade do interior de Minas Gerais.

\section{Instrumento e material}

Foram realizadas atividades de consciência metatextual, conforme Ferreira e Spinillo (2003).

As histórias utilizadas foram: Meus lápis de cor são só meus (Rocha, 2009), O aniversário da sardinha (Alão, s.d.), O amigo da bruxinha (Furnari, 1998), A borboleta cinza (Vale, s/d), Menina não entra (Andrade, s/d), O elefante sem tromba (Cestari, s.d.), O menino maluquinho (Ziraldo, s.d.), História de uma flor (Brandão \& Spinillo, 2001), A baleia alegre (s.d.), O caracol invejoso (s.d.), O ursinho desavergonhado (s.d.), A lebre e a tartaruga (s.d.) e O cavalo descontente (s.d.).

\section{Procedimentos}

Obtida a permissão das instituições, os responsáveis e as crianças assinaram o Termo de Consentimento Livre e Esclarecido. 
A coleta de dados foi realizada nas próprias dependências das escolas, e consistiu, inicialmente, na coleta da escrita de uma história em situação livre.

A seguir, cada criança, individualmente, encontrou-se com a pesquisadora e escutou dela uma históriaexemplo, marcada em cores diferentes, assim como a explicação acerca das principais partes de uma história, seu início, meio e fim. Tal atividade consistiu na instrução explícita sobre as partes da história e do que elas tratam. Nessa mesma etapa, outra história foi dada à criança para que ela sozinha repetisse o exercício, colorindo com cores sortidas cada uma das partes da história que ela julgava ser a inicial, a do meio e a final.

A segunda etapa da intervenção também aconteceu individualmente. Duas atividades foram realizadas: primeiramente, foram apresentadas 7 gravuras em sequência, as quais correspondiam a uma história que era lida pela pesquisadora. Essa história não continha texto, apenas figuras, que eram embaralhadas, e a criança identificava as gravuras relativas ao início, ao meio e ao fim. A partir daí, foram apresentadas gravuras de outra história, sendo solicitado à criança que a organizasse e produzisse uma história oral de acordo com a sequência das gravuras. Na segunda atividade, foram lidas para a criança as partes de quatro histórias, solicitando-se que ela as identificasse.

A última etapa consistiu em um baralho de histórias. Duas histórias foram recortadas em partes que também representavam o início, o meio e o final de um texto. Embaralhadas as cartas, a criança, acompanhada da pesquisadora, separava as histórias, inicialmente, pensando apenas no tema. A partir dessa separação, foi estruturada a história, dando-se sentido ao texto. Posteriormente, a criança realizou a mesma atividade, porém com o montante de três histórias embaralhadas.

Finalmente, em sala de aula, com todos os alunos juntos, em situação livre, foi pedido que eles escrevessem uma nova história.

\section{Tratamento dos dados}

As histórias foram lidas, e, a seguir, classificadas em categorias e níveis. As categorias progrediam de I até IV, e identificavam o desenvolvimento de aquisição do esquema narrativo, segundo Spinillo (2001). Os níveis cresciam de I a III e versavam sobre as características da narrativa: resolução da situação-problema e desfecho, conforme Rodrigues (2007).

\section{Resultados}

De acordo com a análise dos dados, as histórias das 23 crianças da primeira série, feitas antes e depois da intervenção, foram classificadas em categorias de desenvolvimento do esquema narrativo.

Tabela 1. Frequência de histórias da primeira série em categorias de produção no pré e no pós-teste

\begin{tabular}{lcl}
\hline Esquema narrativo & Pré-teste & Pós-teste \\
\hline Categoria I & 7 & 4 \\
Categoria II & 9 & 12 \\
Categoria III & 7 & 5 \\
Categoria IV & 0 & 2 \\
\hline
\end{tabular}


De acordo com a Tabela 1, observou-se que, na primeira série, na situação pré-teste, as histórias se concentraram na categoria II, seguida das categorias I e III.

Na situação pós-teste, as histórias se concentraram na categoria II, seguida das categorias III, I e IV. Observa-se uma progressão diferenciada da situação anterior, e ressalta-se que, no pós-teste, duas crianças elaboraram histórias classificadas na categoria IV, considerada de maior complexidade.

Ainda segundo análise da primeira série, as narrativas foram classificadas quanto ao nível do desfecho das histórias, se não elaborado, pouco ou elaborado. Nesse caso, obteve-se a seguinte pontuação:

Tabela 2. Frequência de histórias da primeira série quanto ao desfecho no pré e no pós-teste.

\begin{tabular}{lcl}
\hline Desfecho da história & Pré-teste & Pós-teste \\
\hline Nível I & 6 & 4 \\
Nível II & 16 & 12 \\
Nível III & 1 & 7 \\
\hline
\end{tabular}

Na primeira série, na situação pré-teste, os desfechos das histórias se concentraram no nível II, seguido dos níveis I e III.

Na situação pós-teste, os desfechos das histórias se concentraram no nível II, seguido dos níveis III e I. Observa-se progressão diferenciada da situação anterior, ressaltando-se que, no pós-teste, aumentou o número de crianças que elaboraram histórias classificadas no nível III, considerado desfecho elaborado.

Ainda de acordo com esses dados, observa-se que houve diminuição das histórias com desfecho no nível I, assim como daquelas no nível II, nomeadas como desfecho não elaborado e pouco elaborado.

A seguir, exemplos de histórias que evoluíram em seus níveis de desfecho:
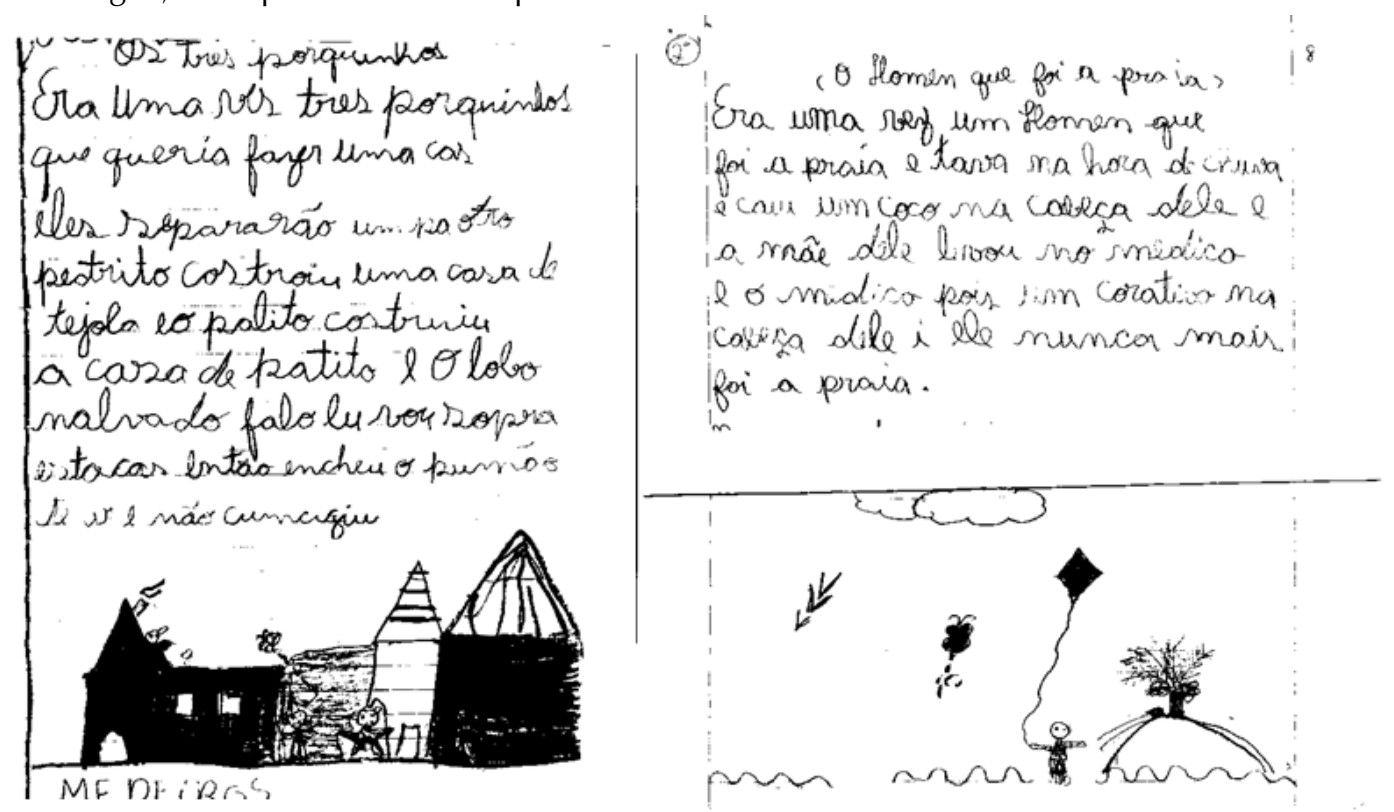

Figura 1. Histórias de um aluno da $1^{\text {a }}$ série antes e depois da intervenção 
Quanto aos resultados da terceira série, as histórias das 50 crianças, feitas inicialmente, foram classificadas quanto ao desenvolvimento do esquema narrativo que apontou a seguinte categorização:

Tabela 3. Frequência de histórias da terceira série em categorias de produção no pré e no pós-teste

\begin{tabular}{lcl}
\hline Esquema narrativo & Pré-teste & Pós-teste \\
\hline Categoria & 9 & 2 \\
Categoria & 26 & 21 \\
Categoria & 10 & 22 \\
Categoria & 15 & 5 \\
\hline
\end{tabular}

Na terceira série, na situação pré-teste, as histórias se concentraram na categoria II, seguida das categorias III, I e IV.

Observa-se que, após a intervenção, as histórias das crianças da terceira série passaram a se concentrar na categoria III, seguida da II, IV e I.

Ainda segundo a análise, as histórias foram classificadas quando à resolução da situação-problema, se sem coerência, não explicada ou explicada. Nesse caso, obteve-se a seguinte pontuação:

Tabela 4. Frequência de histórias da terceira série quanto à resolução da situação-problema no pré e no pós-teste

\begin{tabular}{lcc}
\hline Desfecho da história & Pré-teste & Pós-teste \\
\hline Nível & I & 17 \\
Nível & II & 23 \\
Nível & III & 10 \\
\hline
\end{tabular}

Na terceira série, na situação pré-teste, a resolução da situação-problema se concentrou no nível II, seguido dos níveis I e III.

Na situação pós-teste, a categorização da resolução da situação-problema se concentrou no nível II, seguido dos níveis III e I.

Observando-se a Tabela 4, percebe-se que o número de histórias no nível II permaneceu quase o mesmo. Entretanto, dobrou o número de histórias no nível III e, em consequência, diminuíram para menos da metade aquelas categorizadas no nível I.

A seguir, exemplos de histórias que evoluíram em seus níveis de resolução-problema: 

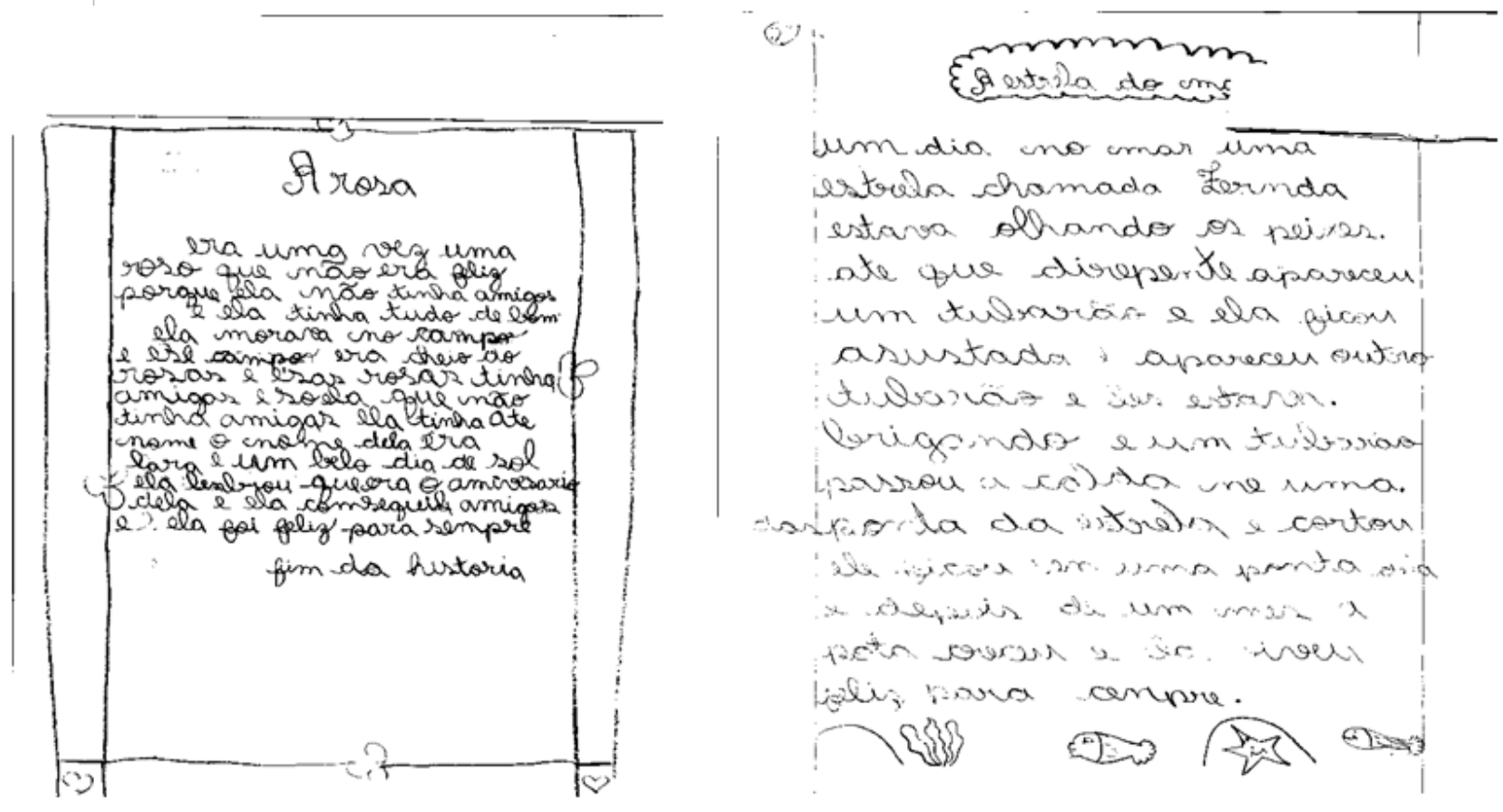

Figura 2. Histórias de uma aluna da $3^{\mathrm{a}}$ série antes e depois da intervenção

\section{Discussão}

A discussão acerca dos resultados descritos refere-se à possível influência das atividades de consciência metatextual sobre as categorias de produção dos textos narrativos, das crianças de 7 e 9 anos, bem como sobre os níveis do desfecho da história e da resolução da situaçãoproblema, respectivamente.

Se tomarmos os dados apresentados na Tabela 1, não houve mudança entre o pré e o pós-teste quanto ao fato de a maioria das histórias dos alunos da primeira série ter sido classificada na categoria II. Entretanto, é possível pensar na progressão dos textos desses alunos, visto que, após a intervenção, foram escritos dois textos na categoria IV, na qual as histórias são completas, com uma estrutura narrativa elaborada. Finalmente, diminuíram as produções na categoria I, nas quais havia apenas introdução da cena e dos personagens, com a presença de marcadores linguísticos convencionais do começo de uma história.

Adotando as categorias acima, estudos de Spinillo, (2001) indicaram que crianças entre 6 e 7 anos escrevem histórias bastante variadas, que se distribuem entre as categorias II e IV. Observa-se concordância com a autora, adicionando-se a percepção de que, dentre os participantes desta pesquisa, alguns escreveram histórias elementares classificadas na categoria I. Assim, ressaltase que a variação apresentada pelas histórias das crianças da 1ạ série possibilita pensar que elas alcançaram, por meio das atividades de consciência metatextual, êxito na progressão da escrita. Sobre esse aspecto, do domínio do esquema narrativo, segundo Silva e Spinillo (2000), a progressão na escrita de narrativas é pouco expressiva no primeiro ano de escolaridade. Nesse caso, a escolarização é fator importante no desenvolvimento do esquema narrativo. 
Sobre os níveis do desfecho da história, na primeira série, na situação pós-teste, estes continuaram concentrados no nível II. Nesse caso, a maioria das crianças produziu um desfecho de narrativa não explicado. Nessas histórias, conforme classificação de Spinillo e Martins (1997), verificam-se vários eventos conectados entre si e um tema central mantido ao longo de toda a narração, com um desfecho que não apresenta relação clara com o evento principal.

Com base nesse estudo, considera-se que os alunos da primeira série, participantes desta pesquisa, que apresentaram em suas histórias desfecho não explicado, já ultrapassaram a dificuldade relativa à definição e à manutenção do tópico ao longo da narrativa, mas ainda apresentam dificuldades referentes à elaboração de um desfecho relacionado ao evento principal e aos episódios narrados. Entretanto, acreditase que o aumento das histórias com desfecho elaborado tenha sido influenciado pela situação de produção. Supõe-se que, nas histórias das crianças de 7 anos, a situação com atividades de consciência metatextual tenha favorecido a emergência de um tipo de desfecho ainda difícil de ser alcançado nessa idade.

Quanto à terceira série, após a intervenção, as histórias das crianças se concentraram na categoria III, relativa a desfechos explicados. Tomando os dados apresentados na Tabela 3, enfatiza-se a evolução das histórias. Houve diminuição das menos elaboradas, classificadas nas categorias I e II, e aumento do número das mais elaboradas. Isso leva a pensar na eficácia da intervenção junto a essas crianças. No entanto, esses dados devem ser complementados a partir do trabalho de Silva e Spinillo (2000), no qual as autoras pontuam que, dentre os grupos de crianças cujas produções escritas são elementares, intermediárias ou elaboradas, as que estarão mais sujeitas à influência de uma situação de produção são aquelas que estiverem escrevendo narrativas classificadas como intermediárias. No entanto, como as histórias das crianças não foram classificadas separadamente, não se verificou quais produções foram influenciadas pela intervenção.

Sobre a resolução da situação-problema, mesmo mantendo a concentração no nível II, entre o pré e pós-teste, percebeu-se a diminuição para menos da metade das histórias com resolução sem coerência e a duplicação do número daquelas explicadas. Foi visto que o fato de a criança elaborar uma narrativa antes ou depois da intervenção alterou a característica resolução da situação-problema explicada. Conforme pôde ser checado, os participantes de 9 anos evidenciaram 10 vezes esse tipo de resolução na situação pré-teste e 20 vezes na situação pós-teste. Aferidos os resultados apresentados sobre essa característica, o que chamou a atenção foi a diferença da sua manifestação, típica de histórias elaboradas, após a intervenção.

Sobre as narrativas das crianças de nove anos que evidenciaram resolução da situaçãoproblema explicada, na situação de produção após as atividades de consciência metatextual, supõe-se que essa característica seja mais suscetível de ser influenciada nessa idade. Essa hipótese se fundamenta em pesquisa de Brandão e Spinillo (1998), na qual se examinou a relação entre o tipo de resposta fornecido e os elementos estruturais de uma história, a saber: situação-problema, resolução da situação-problema e conclusão. As autoras identificaram que as respostas precisas são inicialmente mais frequentes diante das perguntas relacionadas à situaçãoproblema do que nas perguntas sobre a resolução do problema e a consequência; a seguir, as respostas precisas ocorrem mais nas questões relacionadas à situação-problema e à consequência do que nas perguntas sobre a resolução do problema. 
Em analogia com essa pesquisa, pode-se supor que esse padrão evolutivo se mantém, a saber: os elementos estruturais da história seriam apreendidos pelas crianças na seguinte ordem: situação-problema, desfecho e resolução da situação-problema. Nesse contexto, a resolução da situação-problema seria a característica mais importante a ser desenvolvida nas narrativas das crianças de nove anos.

Por último, destaca-se a relevância de pesquisas a respeito das situações de produção de textos propriamente dita. Essa é, segundo a opinião das autoras, a maior produção na área educacional, que tem sido investigada sobretudo em nível da escrita. Sem dúvida, essa última é um importante objetivo escolar. Entretanto, o que se percebe é que, ao lado de uma produção sobre o aspecto didático da produção de textos, há pouco conhecimento sobre a adequação pedagógica aos aspectos cognitivos dos alunos. O estudo dos aspectos cognitivos envolvidos na produção de histórias teria como decorrência tanto a sua contribuição na elaboração e na sedimentação teórica sobre o desenvolvimento do pensamento narrativo quanto a possibilidade de repensarmos as práticas pedagógicas de exercício narrativo. Dessa forma, a partir de estudos complementares, poderiam ser investigadas novas formas de interferência, que fornecessem sugestões, situações nas quais as crianças pudessem desenvolver o pensamento e sua habilidade de narrar histórias. Inclui-se aí o cuidado com a situação de produção, na qual as atividades de consciência metatextual ocupassem um lugar de destaque.

\section{Considerações finais}

Dentre as atividades de narrar, a proposta do presente estudo era a de influenciar a elaboração de textos narrativos por meio de uma situação de produção com atividades de consciência metatextual. A referida situação foi pesquisada nas idades de 7 e 9 anos, na primeira e na terceira série, respectivamente. No que se refere às variáveis idades e situação de produção, pretendia-se analisar a influência das atividades de consciência metatextual na produção de textos narrativos, especificamente nos seguintes aspectos: categorias de desenvolvimento e níveis das características das narrativas das crianças de 7 e 9 anos e comparação das categorias e características das narrativas das crianças em função da situação de produção.

Quanto à situação de produção das narrativas, na comparação das categorias de desenvolvimento das narrativas das crianças de 7 e 9 anos, antes e depois da intervenção, a maior parte das narrativas mais elaboradas foi realizada após a intervenção.

Entretanto, desse resultado, dois pontos chamam a atenção: o primeiro é que a intervenção pareceu contribuir para a presença de características elaboradas da narrativa, mas não influenciou as categorias das narrativas; o segundo é que a influência foi diferente entre as idades.

Assim sendo, passar-se-á ao primeiro ponto: ainda que as diferenças observadas entre as categorias não tenham sido significativas, na comparação entre as idades dos participantes de 7 e de 9 anos, estes indicaram modos de realização das narrativas. Desde aquelas da categoria I até a categoria IV, passando pelas categorias II e III, considerou-se como primeira categoria as produções nas quais havia introdução da cena e dos personagens, com a presença de marcadores linguísticos convencionais do começo de uma história, do tipo Era uma vez, o que teve como consequência a elaboração de narrativas com excesso de ligações, sem que fosse possível verificar as relações existentes entre os elementos, concepção das partes de um todo de forma independente umas das 
outras, um tipo elementar de resolução da situação-problema e mudança de tópicos ao longo da narração, sem que se retornasse ao evento principal no final. No outro extremo, as narrativas típicas da categoria IV basearamse em características que permitiram um tipo de resolução da situação-problema explicada e a elaboração de um desfecho em conexão com os eventos narrados no desenvolvimento da história. As histórias eram completas, com uma estrutura narrativa e desfecho da trama elaborados. Entre essas categorias, surgiu a II e a III, com a predominância de características que tiveram como consequência um tipo de resolução coerente da situação-problema, mas não explicado, e um desfecho que apresentava relação com o evento principal, mas o final da história não era elaborado. Essas histórias apresentavam uma ação que sugeria o esboço de uma situação-problema, e mostravam tentativas de resolução da situaçãoproblema sem que fossem explicitados os meios utilizados.

Contudo, a predominância de características elementares, intermediárias ou elaboradas na formulação dos níveis I, II, e III, respectivamente, não garantiu diferenças significativas entre as narrativas das crianças de 7 e 9 anos, nas situações de produção antes e depois da intervenção. A análise da discrepância desse resultado, a saber, a presença perceptível de características elaboradas em narrativas na situação de produção pós-teste e o fato de as melhores narrativas das crianças de 9 anos terem aparecido nessa situação de produção indica, portanto, um caminho para reflexão que se refere à possibilidade de se utilizar mais histórias de crianças em idades diferentes, no sentido de aperfeiçoar a própria formulação dos níveis, especialmente os das características da narrativa, para os quais a literatura à qual se teve acesso foi menos específica.
O segundo item dos resultados gerais consistiu no fato de que a situação de produção pareceu influenciar diferentemente as narrativas das crianças de 7 e 9 anos.

Conforme foi identificado, as narrativas das crianças de 7 anos apresentaram mais, na situação de produção após as atividades de consciência metatextual, as características desfecho elaborado, enquanto as narrativas das crianças de 9 anos, na mesma situação de produção, apresentaram mais a característica resolução da situação-problema explicada.

Assim, pode-se perguntar se a criança, nessa idade, sente como nós a necessidade de uma explicação para a história. Essas considerações podem ser contextualizadas, sob o desenvolvimento cognitivo, com a constatação de que a criança, por volta de 6 a 8 anos, pouco se interessa pela forma como as coisas acontecem. A sua curiosidade é global. A vida é para ela uma espécie de história, organizada ao sabor dos desejos e das intenções do seu inventor.

Para que as crianças demonstrem as noções de resolução da situação-problema e desfecho, se o tempo é um dos fatores indicadores desse desenvolvimento, surge então o questionamento sobre a influência da situação de produção no aparecimento dessas características.

Tal como acontece com o aprendizado da linguagem, a contribuição social é muito importante para o desenvolvimento da competência narrativa da criança e consequente capacidade para contar histórias. As crianças percebem rapidamente como os outros contam histórias e passam a utilizar os mesmos procedimentos, cada vez mais, no decorrer do tempo. A apreensão da estrutura de uma narrativa, apesar de implicar uma complexidade a ser gerenciada por ela do ponto de vista cognitivo, fornece-lhe novas estratégias para lidar com essa complexidade, 
que se traduzem em técnicas diferentes da organização de personagens e eventos. Ao facilitar a imaginação e o simbolismo da criança disponibilizando um espaço para o seu exercício, as atividades narrativas preparam o caminho para o desenvolvimento do pensamento abstrato.

Assim sendo, se a capacidade de contar histórias for entendida como resultante do processo de interação da criança com os acontecimentos que vivencia e com as pessoas com as quais aprende a narrar, e se o exercício narrativo for considerado uma atividade importante no desenvolvimento da própria capacidade de narrar, então é importante compreender aspectos dessa atividade, de tal maneira a serem fornecidos à criança novos mecanismos, técnicas e meios para que suas competências e inspirações encontrem maneiras mais ricas de expressão e de desenvolvimento.

O resultado desta pesquisa soma-se favoravelmente ao fato de os educadores considerarem a produção das histórias infantis um desafio à sua prática pedagógica. Nesse contexto, alerta-se para a importância das adaptações escolares dos dados encontrados em estudos sobre situações favoráveis à produção de histórias e do planejamento de atividades que tenham como objetivo levar os alunos a refletir sobre a estrutura de uma história. Assim sendo, não se trata de conceber as características formais da narrativa como noções que devam ser ensinadas à criança, mas acredita-se que, no exercício narrativo, é possível que ela descubra, portanto, construa, por meio de uma experiência ativa, a noção da estrutura das histórias, ampliando assim o seu próprio repertório narrativo.

Implicações educacionais relevantes podem ser extraídas de estudos que identifiquem aspectos que favoreçam a escrita de textos.
Nesses estudos, seria importante que o próprio professor, a partir de uma capacitação específica, ministrasse as intervenções em sala de aula. Dessa forma, ao considerar a importância desse achado e seu direcionamento para a realidade escolar, é necessário caminhar para esse ideal de intervenção, conduzindo estudos por meio dos quais se investiguem as correlações existentes entre eventos de uma história e desenvolvimento dessas noções na criança.

Enfatiza-se que, em todas as situações de produção de histórias assinaladas até o presente momento por meio de citações da literatura, pôde-se perceber a importância do tipo de relação entre situação de produção e formulação dos textos da própria criança, se elementares, intermediários ou elaborados.

Entretanto, o efeito da situação de produção sobre a escrita de textos parece não ser o mesmo para todas as crianças. Existem aquelas que são mais sensíveis do que as outras.

Todas essas considerações convergem, portanto, para o fato de que há um percurso de desenvolvimento da narrativa influenciada pela escolaridade e pelas experiências. Nesse contexto, as situações de produção são também importantes fatores a serem considerados, quando se deseja examinar as habilidades que a criança possui e as dificuldades que experimenta.

Assim, a situação de produção, veiculada pela participação em atividades de consciência metatextual com uma história antes de escrevê-la, é um dos pequenos pontos que formam a diversidade de experiências com narrativas, sendo que essa situação demonstrou influenciar as características elaboradas de uma narrativa. E é essa a tarefa do próprio exercício narrativo, ou seja, dar forma ao imaginário da criança, emprestando- 
Ihe concretude de maneira a abrir caminho para o pensamento abstrato, sem que se perca a riqueza da imaginação, via ficção e arte.

Ressalta-se que a problemática deste artigo está sendo investigada também em adolescentes, em contexto de educação especial, por meio de um projeto de iniciação científica com o apoio da Fundação de Amparo à Pesquisa do Estado de Minas Gerais. Nesse caso, os contos foram adaptados para textos mais apropriados aos participantes. Dessa forma, eles escreveram e contaram histórias, antes e depois da intervenção, que se encontram em fase de análise.

É destaque, também, a importância da realização desses estudos, principalmente com uma contextualização das produções das narrativas de acordo com o local onde são elaboradas e com o seu entorno. Seguir a evolução da capacidade de contar histórias em crianças de escolas regulares e especiais certamente ajudará a compreender melhor a importância da escolarização ao se construir a habilidade de contar histórias. Adiciona-se, a essa contextualização, a análise dos serviços de biblioteca e o contexto familiar favorável à leitura. 
Maria do Rosário de Fátima Rodrigues

Doutora em Psicologia pela Universidade Federal do Espírito Santo. Mestre em Psicologia pela Pontifícia Universidade

Católica de Campinas. Professora do Centro Universitário do Leste de Minas Gerais, Minas Gerais - MG - Brasil.

E-mail: rosariopsi@yahoo.com.br

\section{Fernanda Costa Vilela}

Graduada em Psicologia pelo Centro Universitário do Leste de Minas Gerais, Minas Gerais, MG - Brasil.

E-mail: fernandacv1304@hotmail.com

\section{Endereço para envio de correspondência:}

Centro Universitário do Leste de Minas Gerais - Curso de Psicologia

Av. Tancredo Neves, 3500, B. Universitário Coronel Fabriciano, Belo Horizonte - MG - Brasil. CEP 35170-056

Recebido 25/5/2010, 1a Reformulação 14/9/2011, Aprovado 10/1/2012. 


\section{Referências}

A baleia alegre. (s.d) Recuperado em 05 julho, 2011, de: http:// www.metaforas.com.br/infantis/baleiaalegre.htm

Alão, M. H. J. (s.d.). O aniversário da sardinha. Recuperado em 5 novembro, 2009, de Contos e Poesia: http:// www.contos.poesias.nom.br/oaniversariodasardinha/ oaniversariodasardinha.htm.

A lebre e a tartaruga. (s.d.) Recuperado em 5 julho, 2011, de http://www.metaforas.com.br/infantis/a_lebre_ea_tartaruga. htm.

Andrade, T. G. C. (2006). Menina não entra. Brasil: Editora do Brasil.

Brandão, A. C. P., \& Spinillo, A. G. (1998). Aspectos gerais e específicos na compreensão de textos. Psicologia: Reflexão e Crítica, 11(2), 253-272.

Brandão, A. C. P., \& Spinillo, A. G. (2001). Produção e compreensão de textos em uma perspectiva de desenvolvimento. Estud. Psicol., 6(1). Recuperado em 5 julho, 2011, de: http://www. scielo.br/scielo.php?script=sci_arttext\&pid=S1413-294X200 $1000100006 \&$ Ing $=$ en\&nrm $=$ iso.

Cestari, M. W. de O. (s.d.). O elefante sem tromba. Recuperado em 5 julho, 2011, de http://leiladavano.blogspot.com/2009/09/ o-elefante-sem-tromba.html.

Ferreira, A. L., \& Spinillo, A. G. (2003). Desenvolvendo a habilidade de produção de textos em crianças a partir da consciência metatextual. In M. R. Maluf (Org.), Metalinguagem e aquisição da escrita: contribuições da pesquisa para a prática da alfabetização (pp. 119-148). São Paulo: Casa do Psicólogo.

Furnari, E. (1998). O amigo da bruxinha. São Paulo: Editora Moderna.

Jakobson R. (s.d.). Linguística e comunicação. (I. Blikstein \& J. P. Paes, trads.). São Paulo: Cultrix.

Maluf, M. R., Zanella, M. S., \& Pagnez, K. S. M. M. (2006). Habilidades metalingüísticas e linguagem escrita nas pesquisas brasileiras. Boletim de Psicologia, 56(124), 67-92.

O caracol invejoso. (s.d.). Recuperado em 5 julho, 2011, de: http://www.metaforas.com.br/infantis/caracol.htm.

O cavalo descontente. (s.d.). Recuperado em 5 julho, 2011, de: http://www.metaforas.com.br/infantis/cavalo.htm.

O ursinho desavergonhado. (s.d.) Recuperado em 5 julho, 2011, de: http://poesiasefatos.blogspot.com/2010/06/o-ursinhodesavergonhado-fabula.html.
Rocha, R. Meus lápis de cor são só meus. (s.d.) Recuperado em 5 novembro, 2009, de Ruth Rocha: http://www2.uol.com.br/ ruthrocha/historias_01.htm.

Rodrigues, M. R. F. (2007). A influência do desenho na produção de textos narrativos em crianças de 7 e 9 anos. Tese de doutorado, Universidade Federal do Espírito Santo, Vitória, ES.

Silva, M. E. L., \& Spinillo, A. G. (2000). A influência de diferentes situações de produção na escrita de histórias. Psicologia: Reflexão e Crítica, 13(3), 337-350.

Spinillo, A. G. (2001). A produção de histórias por crianças: a textualidade em foco. In J. Correa, A. G. Spinillo \& S. Leitão. (Orgs.), (2001). Desenvolvimento da linguagem: escrita e textualidade (pp. 73-116). Rio de Janeiro: NAU Editora.

Spinillo, A. G., \& Martins, R. A. (1997). Uma análise da produção de histórias coerentes por crianças. Psicologia: Reflexão e Crítica, 10(2), 219-248.

Spinillo, A. G., \& Simões, P. U. (2003). O desenvolvimento da consciência metatextual em crianças: Questões conceituais, metodológicas e resultados de pesquisas. Psicologia: Reflexão e Crítica, 16(3), 537-546.

Vale, M. (s.d.). A borboleta cinza. Belo Horizonte: Dimensão.

Walty, I., \& Cury, M. Z. (1999). Textos sobre textos: um estudo da metalinguagem. Belo Horizonte: Dimensão.

Ziraldo. O menino maluquinho. (s.d.) Recuperado em 5 julho, 2011, de: http://www.portalsaofrancisco.com.br/alfa/literaturainfantil-classicos-infantis/o-menino-maluquinho1.php. 